\title{
Study of Prescribing Pattern of Antihypertensive Drugs and Evaluation of the Prescription with JNC 8 Guidelines in North Karnataka Hospital
}

\author{
Ashok Kumar Malpani*, Manjunath Waggi, Palash Panja, Thella Monica Christien \\ Rajiv Memorial Education Society's College of Pharmacy, Old Jewargi Road, Gulbarga, Karnataka-585102, INDIA.
}

\begin{abstract}
Aim: To conduct a prospective observational study on prescribing pattern of antihypertensive drugs and to evaluate the current practice of antihypertensive drug by comparing with JNC-8 guidelines in north Karnataka hospital. Methods: The study was conducted for a period of 6 months with a sample size of 100 of all the in-patient of age $\geq 18$ years of hypertension with or without co-morbidities, including pregnant women and lactating mothers. Results: A total of 100 prescriptions were analysed during the six-month study period. $55 \%$ were male while $45 \%$ were female. $25 \%$ patients received monotherapy while majority of the patient's i.e. $75 \%$ were put on multidrug therapy of which, $35 \%$ patients on two drug therapy, $32 \%$ of patients on three drug therapy and $8 \%$ on four drug therapy. The most common drug classes involved in the study were ARBs $(17 \%)$, BBs $(09 \%)$ and ACEIs $(03 \%)$. Our study reveals that without diabetes or CKD (greater than 60 years) $75.60 \%$ of patients were compliant with JNC-8 goal (less than $150 / 90 \mathrm{mmHg}$ ) and without diabetes or CKD (less than 60 years) $64.30 \%$ of patients were compliant with JNC- 8 goal (less than $140 / 90 \mathrm{mmHg}$ ). Patients with diabetes and without CKD (all ages) 50\% achieved the JNC-8 goal (less than 140/90 $\mathrm{mmHg}$ ) and Patients with CKD or without DM (all ages and races) $60 \%$ achieved the JNC-8 goal (less than 140/90 mmHg). Conclusion: Calcium channel blockers (Amlodipine) and diuretics (Furosemide) were the drug of choice for hypertensive patients as a single drug and combination drug therapy. As per the JNC 8 guidelines majority of the BP goals were achieved. Our result reveals that antihypertensive medication adherence to JNC 8 guidelines is optimal at the study site.
\end{abstract}

Key words: Prescription pattern, Anti-hypertensive, In-patients, JNC-8, Co-Morbidities

\section{INTRODUCTION}

Hypertension is not a disease but an important risk factor for cardiovascular complications. It is defined as a condition in which blood pressure is elevated to an extent where benefit is obtained from blood pressure lowering. ${ }^{1}$ Hypertension refers to prolonged and persistent elevation of blood pressure above the normal range. If not treated properly, hypertension can cause severe complications such as stroke, coronary heart disease and kidney failure. Patient with hypertension must take antihypertensive drugs on a long term basis. Although such drugs cannot give a radical cure, they can prevent heart failure, kidney failure and acute stroke induced by hypertension and delay the development of atherosclerosis by controlling the blood pressure. Generally speaking antihypertensive drugs must be taken for life time. ${ }^{2}$ It is estimated that 972 million adults were affected by hypertension worldwide, with $66 \%$ of those affected were from low and middle income countries. Hypertension is directly responsible for $57 \%$ of all stroke deaths and $24 \%$ of all coronary heart disease deaths in India. ${ }^{3}$

According to Directorate General of
DOI: 10.5530/ijopp.11.4.40

Address for correspondence: Prof. Dr Ashok Kumar Malpani, Rajiv Memorial Education Society's College of Pharmacy, Old Jewargi Road, Gulbarga, Karnataka-585102, INDIA. Phone no: +91 9845407765 Email Id: malpani_ashok@ rediffmail.com

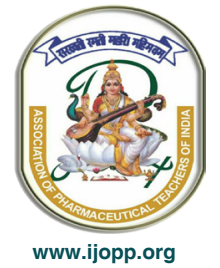


Health Services, Ministry of Health and Family Welfare, Government of India, the overall prevalence of hypertension in India by 2020 will be 159.46/1000 population. ${ }^{4}$

\section{MATERIALS AND METHODS}

A Prospective observational study was carried out for the period of six months in the In-patient department of North Karnataka Hospital. Prescriptions were analysed during the study period. All the of age $\geq 18$ years with or without co-morbidities, including pregnant women and lactating mother who were diagnosed with hypertension as per JNC 8 guidelines and receiving antihypertensive drugs were included. Patient's data relevant to the study was obtained from the patients clinical records.

\section{RESULTS}

\section{Age and Gender Group Distribution of Patient}

Most of the male and female hypertensive patients were

\begin{tabular}{ccccc} 
Table 1: Age group distribution of patients. & \\
Category & $\begin{array}{c}\text { less than } \\
\text { 40years }\end{array}$ & $\begin{array}{c}\mathbf{4 0 - 6 0} \\
\text { years }\end{array}$ & $\begin{array}{c}\text { Greater than } \\
\mathbf{6 0} \text { years }\end{array}$ & Total \\
\hline Male & 09 & 27 & 19 & 55 \\
Female & 02 & 28 & 16 & 45 \\
\hline
\end{tabular}

\section{Table 2: Comorbidities of the patients.}

\begin{tabular}{ccc} 
Comorbidity & Number of Patient & Percentage (\%) \\
\hline CVA & 21 & 29.59 \\
COPD & 10 & 14.09 \\
Diabetes Mellitus(DM) & 09 & 12.68 \\
IHD & 07 & 09.87 \\
CKD & 05 & 07.04 \\
MI & 02 & 02.81 \\
CCF & 02 & 02.81 \\
ALD & 02 & 02.81 \\
Asthma & 02 & 02.81 \\
GE & 02 & 02.81 \\
Hemiplegia & 02 & 02.81 \\
Malaria & 01 & 01.41 \\
LVF & 01 & 01.41 \\
Arthritis & 01 & 01.41 \\
Hepatitis & 01 & 01.41 \\
Angina & 01 & 01.41 \\
Hypoglycemia & 01 & 01.41 \\
Renal caliculli & 01 & 01.41 \\
\hline & &
\end{tabular}

in the age group of 40-60 years shown in Table 1.

\section{Comorbidities of the Patients}

Out of 100 patients, comorbidity was found in 71 subjects, the most common one being CVA $(29.59 \%)$ followed by COPD (14.09\%) and others shown in Table 2.

\section{Number of drugs prescribed}

The numbers of combinational drugs which are prescribed are shown in Table 3.

\section{Frequency of Administration of Antihypertensiveses}

$\mathrm{CCBs}$ and Diuretics were the most commonly prescribed group with equal frequency (43\%), the next common group in the order was ARBs (17\%), BB is $(09 \%)$ and

\begin{tabular}{lcc}
\hline \multicolumn{2}{|c|}{ Table 3: Number of Drugs Prescribed. } & \\
\hline Number Of Antihypertensive & $\begin{array}{c}\text { Total } \\
\text { Number of } \\
\text { Prescription }\end{array}$ & $\begin{array}{c}\text { Percentage } \\
\text { (\%) }\end{array}$ \\
\hline $\begin{array}{c}\text { Mono Drug ( CCB, D, ARB, } \\
\text { ACEI) }\end{array}$ & 25 & 25 \\
Two Drugs( CCB+D, D+ARB) & 35 & 35 \\
Three Drugs (MANNITOL+ \\
$\begin{array}{c}\text { D+CCB, D+CCB+D) } \\
\text { Four Drug }\end{array}$ \\
$\begin{array}{c}\text { (D+CCB+A+MANNITOL, } \\
\text { D+A+CCB+CCB) }\end{array}$ \\
\hline
\end{tabular}

Table 4: Frequency of Drug Administration (class of drugs prescribed).

\begin{tabular}{|c|c|c|}
\hline ANTIHYPERTENSIVE & NAME OF DRUG & $\begin{array}{l}\text { NUMBER } \\
\text { OF DRUGS }\end{array}$ \\
\hline \multirow{3}{*}{$\begin{array}{c}\text { CALCIUM CHANNEL } \\
\text { BLOCKERS (CCBs) } \\
(43 \%)\end{array}$} & AMLODIPINE & 39 \\
\hline & NEFEDIPINE & 04 \\
\hline & FUROSEMIDE & 26 \\
\hline \multirow[t]{2}{*}{ DIURETICS (43\%) } & SPIRONOLACTONE & 04 \\
\hline & MANNITOL & 13 \\
\hline \multirow{2}{*}{$\begin{array}{c}\text { BETA BLOCKERS (BB) } \\
(09 \%)\end{array}$} & ATENOLOL & 06 \\
\hline & METAPROLOL & 03 \\
\hline $\begin{array}{l}\text { ANGIOTENSIN } \\
\text { RECEPTOR }\end{array}$ & TELMISARTAN & 05 \\
\hline $\begin{array}{c}\text { BLOCKERS (ARBs) } \\
(17 \%)\end{array}$ & LOSARTON & 12 \\
\hline $\begin{array}{c}\text { ANGIOTENSIN } \\
\text { CONVERTING ENZYME } \\
\text { INHIBITORS (ACEI) } \\
(03 \%)\end{array}$ & RAMIPRIL & 03 \\
\hline
\end{tabular}


Table 5: Prescription pattern of antihypertensive drugs.

\begin{tabular}{|c|c|c|c|c|c|}
\hline \multicolumn{2}{|c|}{ MONOTHERAPY } & \multicolumn{2}{|c|}{ THREE DRUG COMBINATION } & \multicolumn{2}{|c|}{ FOUR DRUG COMBINATION } \\
\hline Drug Regimen & No $(\%)$ & Drug Regimen & No $(\%)$ & Drug Regimen & No (\%) \\
\hline ССВ & 15 & $D+D+C C B$ & 16 & \multirow{2}{*}{$D+C C B+A R B+D$} & \multirow{2}{*}{01} \\
\hline $\mathrm{D}$ & 08 & $D+C C B+D$ & 03 & & \\
\hline ARB & 04 & $D+A R B+C C B$ & 02 & \multirow{2}{*}{$\mathrm{D}+\mathrm{ARB}+\mathrm{CCB}+\mathrm{CCB}$} & \multirow{2}{*}{01} \\
\hline ACE & 02 & $D+C C B+B B$ & 02 & & \\
\hline \multicolumn{2}{|c|}{ TWO DRUG COMBINATION } & $\mathrm{D}+\mathrm{CCB}+\mathrm{CCB}$ & 01 & \multirow{2}{*}{$\mathrm{D}+\mathrm{CCB}+\mathrm{ARB}+\mathrm{BB}$} & \multirow{2}{*}{01} \\
\hline Drug Regimen & No $(\%)$ & $D+D+A R B$ & 01 & & \\
\hline$C C B+D$ & 28 & $D+C C B+A R B$ & 01 & \multirow{2}{*}{$D+C C B+D+C C B$} & \multirow{2}{*}{01} \\
\hline$D+A R B$ & 03 & $D+A R B+C C B$ & 01 & & \\
\hline $\mathrm{BB}+\mathrm{ACE}$ & 01 & $D+A R B+D$ & 01 & \multirow{2}{*}{$D+D+C C B+B B$} & \multirow{2}{*}{01} \\
\hline $\mathrm{ARB}+\mathrm{CCB}$ & 01 & $\mathrm{CCB}+\mathrm{CCB}+\mathrm{D}$ & 01 & & \\
\hline $\mathrm{CCB}+\mathrm{BB}$ & 01 & $D+A R B+C C B$ & 01 & \multirow{2}{*}{$D+D+C C B+A R B$} & \multirow{2}{*}{01} \\
\hline \multirow[t]{3}{*}{$D+D$} & 01 & $\mathrm{BB}+\mathrm{CCB}+\mathrm{D}$ & 01 & & \\
\hline & & $C C B+D+B B$ & 01 & \multirow{2}{*}{$D+C C B+B B+A R B$} & \multirow{2}{*}{01} \\
\hline & & $D+C C B+D$ & 01 & & \\
\hline
\end{tabular}

Table 6: BP goals as per JNC-8.

\begin{tabular}{|c|c|c|c|c|c|c|}
\hline \multirow[b]{2}{*}{ Disease } & \multirow[b]{2}{*}{ Population } & \multirow[b]{2}{*}{ Goal BP } & \multicolumn{2}{|c|}{ Number of Patients } & \multicolumn{2}{|c|}{ Percentage (\%) } \\
\hline & & & Achieved & $\begin{array}{c}\text { Not } \\
\text { Achieved }\end{array}$ & Achieved & $\begin{array}{c}\text { Not } \\
\text { Achieved }\end{array}$ \\
\hline Without Diabetes Or CKD & Greater than 60 years & less than $150 / 90$ & 31 & 10 & 75.60 & 24.4 \\
\hline Without Or CKD & Less than 60 years & less than $140 / 90$ & 27 & 15 & 64.3 & 35.7 \\
\hline Diabetes Present Without CKD & All Ages & less than $140 / 90$ & 06 & 06 & 50 & 50 \\
\hline With CKD With Or Without Diabetes & All Ages and Racess & less than $140 / 90$ & 03 & 02 & 60 & 40 \\
\hline
\end{tabular}

ACEI is $(03 \%)$ prescribed as shown below in Table 4.

\section{Prescription Pattern of Antihypertensive Drugs}

Our study shows that CCBs were the most commonly prescribed drug under monotherapy (15\%) followed by diuretics $(08 \%)$ and ARB $(04 \%)$ and ACEI $(02 \%)$ respectively. In two drug combination therapy study shows that $\mathrm{CCB}+\mathrm{D}(28 \%)$ were the most commonly prescribed drug followed by $\mathrm{D}+\mathrm{ARB}(03 \%), \mathrm{D}+\mathrm{ARB}$, $\mathrm{B}+\mathrm{ACE}, \mathrm{ARB}+\mathrm{CCB}, \mathrm{CCB}+\mathrm{B}, \mathrm{D}+\mathrm{D}(01 \%)$ respectively. In three drug combination therapy study shows that $\mathrm{D}+\mathrm{D}+\mathrm{CCB}(16 \%)$ were the most commonly prescribed drugs followed by $\mathrm{D}+\mathrm{CCB}+\mathrm{D}(03 \%)$ and $\mathrm{D}+\mathrm{ARB}+\mathrm{CCB}$, $\mathrm{D}+\mathrm{CCB}+\mathrm{B}(02 \%)$ and remaining combination drugs are $01 \%$ respectively. In four drug combination therapy study shows that only $01 \%$ of the prescription contain of each combinational therapy as shown below. (Table 5)

\section{BP Goal as per JNC-8}

According to JNC-8 guidelines out of 41 patients without diabetes or CKD (greater than 60 years) 31 has achieved (75.60\%) the JNC-8 goal ( less than 150/90 mmHg) and patients category of without diabetes or CKD, (less than 60 years) out of 42 patients 27 has achieved $(64.30 \%)$ the goal (lessthan 140/90 $\mathrm{mmHg}$ ). In patient with diabetes and without CKD (all ages), out of 12 patients 06 achieved (50\%) the goal (less than 140/90 $\mathrm{mmHg}$ ) and In CKD present with or without DM (all ages and races), out of 05 patients 03 patients achieved $(60 \%)$ the goal (less than 140/90 mmHg) (Table 6).

\section{DISCUSSION}

The results of our study suggests that out of the total 100 hypertensive patients included in the study, 55\% were male while $45 \%$ were female, indicating the higher prevalence of hypertension in male than in female population.

Our result reveals that the highest number of male hypertensive patients $27 \%$ belonged to the age group of 40-60 years and the highest number of female hypertensive patients $28 \%$ also belonged to the age group of 40-60 years suggesting the earlier onset of hypertension in females than in males. Whereas male 
hypertensive patients belonged to the age group of less than 40 years $(09 \%)$ and above 60 years $(19 \%)$ has the highest number than the female hypertensive patients belonged to the age group of less than 40 years $(02 \%)$ and above 60 years $(16 \%)$. A similar study conducted by Krishna Murti et al. showed that $35 \%$ of male belong to age group of $40-60$ years and $12.4 \%$ of female belong to the age group of above 60 years.

In our study, 25\% patients received monotherapy, while majority of the patient's i.e. $75 \%$ were put on multidrug therapy out of which $35 \%$ patients were on two drug therapy, $32 \%$ of patients on three drug therapy and $08 \%$ on four drug therapy. ${ }^{5}$ Among the monotherapy category the various hypertensive classes prescribed were CCB's (15\%) followed by Diuretics (08\%), ARB's (04\%) and ACEI (02\%) respectively. As a Monotherapy Amlodipine $(15 \%)$ was the most frequently prescribed drug along with furosemide $(08 \%)$, telmisartan $(02 \%)$, losartan $(02 \%)$, and ramipril $(02 \%)$. In the overall utilization pattern of antihypertensive agents, CCB's (43\%) and Diuretics $(43 \%)$ were the most frequently prescribed class of drugs, followed by ARB's (17\%), BB (09\%) and ACEI's (03\%). As compared to Krishna murti et al. out of the total 137 patients $27.73 \%$ patients were received monotherapy, while the majority of the patients $72.26 \%$ were put on multidrug therapy with $68.68 \%$ patients on two drug therapy, $27.27 \%$ patients on three drug therapy and $4.04 \%$ on four drug therapy. Among the monotherapy category the various hypertensive classes prescribed were ranked as follows; diuretics $(28.94 \%)$, followed by CCBs (23.68\%), ACEIs and BBs (18.42\%) and lastly ARBs $(10.52 \%)$. Amlodipine $(21.72 \%)$ was the most frequently prescribed drug as monotherapy along with Thiazides (19.67\%), Metoprolol (18.36\%), Ramipril (15.84\%) and Telmisartan (12.93\%).

The most frequently prescribed 2 drug regimen was a combination therapy of CCB $+\mathrm{D}(28 \%)$ while the most frequently prescribed 3 drug regimen was found to be a combination therapy of Mannitol + D + CCB (16\%).

Out of the total study subjects, $71 \%$ hypertensive patients were found to have other co morbid conditions. Among the total $71 \%$ of co morbid patients, CVA $(29.59 \%)$, COPD (14.09\%), DM (12.68\%), IHD (09.87\%), CKD $(07.04 \%)$ and others. Where as study conducted by Anand R. Kalamdani et al. showed that out of 100 patients, co morbidity was found in 64 subjects, the most common one being Diabetes mellitus (75\%), followed by COPD $(14 \%)$ and others. ${ }^{6}$

According to JNC-8 guidelines ${ }^{7-12}$ our study reveals that in patients without diabetes or CKD (greater than 60 years)
$75.60 \%$ achieved the goal (less than $150 / 90 \mathrm{mmHg}$ ) and patients without diabetes or CKD (less than 60 years) $64.30 \%$ achieved the goal (less than $140 / 90 \mathrm{mmHg}$ ). Patients with Diabetes and without CKD (all ages) 50\% achieved the goal (less than 140/90 $\mathrm{mmHg}$ ) and patients with CKD with or without DM (all ages and races) 60\% achieved the goal (less than 140/90 mmHg), which shows that the hypertensive goals were being achieved in this study.

\section{CONCLUSION}

Calcium channel blockers (Amlodipine) and diuretics (Furosemide) were the drug of choice for treatment of hypertensive patients as a single drug and combination drug therapy. As per the JNC 8 guidelines majority of the BP goals were achieved. Our result reveals that antihypertensive medication adherence to JNC 8 guidelines is optimal at the study site.

\section{ACKNOWLEDGEMENT}

We would like to express our gratitude to everyone who was instrumental in this study. We sincerely thank Dr B N Joshi district surgeon of Govt. district hospital, Gulbarga, without whom this study would not have been possible.

\section{CONFLICT OF INTEREST}

No conflict of interest is declared.

\section{ABBREVIATIONS}

ACEI: Angiotensin converting Enzyme Inhibitor; ARB: Angiotensin receptor blocker; CCBs: Calcium channel Blockers; BBs: Beta blockers; DM: Diabetes Mellitus; CKD: Chronic Kidney Disease; HTN: Hypertension; COPD: Chronic obstructive Pulmonary Disease; IHD: Ischemic Disease; CVA: Cerebrovascular accident; MI: Myocardial Infarction; CCF: Congestive cardiac failure; ALD: Alcohol Liver Disease; GE: Gastroenteritis; LVF: Lower Ventricular Failure; JNC: Joint National Committee; IPD: In patient Department; DDI: Drugdrug Interaction; D: Diuretics.

\section{SUMMARY}

- The most common drug classes involved are Angiotensin receptor blocker followed by Beta Blockers and Angiotensin converting Enzyme 
Inhibitor.

- Calcium channel blockers (Amlodipine) and diuretics (Furosemide) were the drug of choice for treatment of hypertensive patients as a single drug and combination drug therapy.

- As per the JNC 8 guidelines majority of the BP goals were achieved.

\section{REFERENCES}

1. Walker R, Whittlesea C. Clinical Pharmacy and Therapeutics. $4^{\text {th }}$ edition. London: Churchill Livingtone Elsevier. 2007.

2. Harvard Medical School. Health A-to-Z: High blood pressure (Hypertension). Available from:www.patienteducationcenter.org/information/high-blood-pressurehypertension. [26 $6^{\text {th }}$ June 2013]

3. Popuri RS, Malladi SR. Study of Prescriptive Patterns of Anti-hypertensive Drugs in South India. International Journal of Advancements in Research and Technology. 2013;2(6):295.

4. Nitin KN, Ganguly B. Adherence To JNC-VII and WHO-ISH guidelines of antihypertensive medications prescribed to hypertensive patients with comorbid conditions. Indian J Physiol Pharmacol. 2015;59(1):48-56.
5. Murti K, Khan A, Dey A, Sethi M, Das P, Pandey K. Prescription Pattern of AntiHypertensive Drugs in Adherence to JNC- 7 Guidelines. American Journal of Pharmacology and Toxicology. 2015;10(1):27-31.

6. Kalamdani AR, Bhandare B, M.B Hemamalini, M.V Krishna. A Prospective Study of Prescribing Pattern of Antihypertensive Drugs in Tertiary Care Hospital, Bangalore. Journal of Evolution of Medical and Dental Sciences. 2014;2(52):10339-44.

7. Armstrong C. JNC 8 Guidelines for the Management of Hypertension in Adults. American Family Physician. 2014;90(7):503-4.

8. Michael R. The JNC 8 Hypertension Guidelines: An In-Depth Guide. The American Journal of Managed Care. 2014; 1.(https://www.ajmc.com/journals/ evidence-based-diabetes-management/2014/january-2014).

9. Randel A. AHA/ACC/ASH Release Guideline on the Treatment of Hypertension and CAD. American Family Physician. 2015;92(11):1023-30.

10. James PA, Oparil S, Carter BL, Cushman WC, Dennison-Himmelfarb C, Handler J. et al. 2014 Evidence-based guideline for the management of high blood pressure in adults: Report from the panel members appointed to the Eighth Joint National Committee (JNC 8) JAMA. 2014;311(5):507-20.

11. Sindhu PR, Reddy MS. Study of prescriptive patterns of antihypertensive drugs in South India. International Journal of Advancements in Research \& Technology. 2013;2:295-311.

12. Arya SN. Therapeutic challenge of resistant hypertension - Indian Perspective. Medicine Update. $1^{\text {st }}$ Edition India. Jaypee Brothers Medical Publishers Private Limited: 2007. 